\title{
Messenger RNA Levels of XPAC and ERCC1 in Ovarian Cancer Tissue Correlate with Response to Platinum-based Chemotherapy
}

\author{
Meenakshi Dabholkar, Justine Vionnet, Frieda Bostick-Bruton, Jing Jie Yu, and Eddie Reed
}

Medical Ovarian Cancer Section, Medicine Branch, National Cancer Institute, Bethesda, Maryland 20892

\begin{abstract}
Nucleotide excision repair is a DNA repair pathway that is highly conserved in nature, with analogous repair systems described in Escherichia coli, yeast, and mammalian cells. The rate-limiting step, DNA damage recognition and excision, is effected by the protein products of the genes ERCC1 and XPAC. We therefore assessed mRNA levels of ERCC1 and XPAC in malignant ovarian cancer tissues from 28 patients that were harvested before the administration of platinum-based chemotherapy. Cancer tissues from patients whose tumors were clinically resistant to therapy $(n=13)$ showed greater levels of total ERCC1 mRNA $(P=0.059)$, full length transcript of ERCC1 mRNA $(P=0.026)$, and XPAC mRNA $(P=0.011)$, as compared with tumor tissues from those individuals clinically sensitive to therapy ( $n$ $=15$ ). In 19 of these tissues, the percentage of alternative splicing of ERCC1 mRNA was assessed. ERCC1 splicing was highly variable, with no difference observed between responders and nonresponders. The alternatively spliced species constituted $2-58 \%$ of the total ERCC1 mRNA in responders (median $=18 \%$ ) and $4-71 \%$ in nonresponders $($ median $=13 \%)$. These data suggest greater activity of the DNA excision repair genes ERCC1 and XPAC in ovarian cancer tissues of patients clinically resistant to platinum compounds. These data also indicate highly variable splicing of ERCC1 mRNA in ovarian cancer tissues in vivo, whether or not such tissues are sensitive to platinum-based therapy. (J. Clin. Invest. 1994. 94:703-708.) Key words: XPAC • ERCC1 - ovarian cancer • platinum compounds
\end{abstract}

\section{Introduction}

Excision repair of bulky DNA adducts, such as those formed by cisplatin, appears to be mediated by an aggregate of genes, with ERCC and XP proteins being involved in DNA damage recognition and excision (1-3). The human DNA repair genes $\mathrm{ERCCl}^{1}$ (the human excision repair gene cross-complementing

Address correspondence to Eddie Reed, Clinical Pharmacology Branch, National Cancer Institute, National Institutes of Health, 9000 Rockville Pike, Bldg. 10, Rm. 12N226, Bethesda, MD 20892.

Received for publication 15 October 1993 and in revised form 9 February 1994.

1. Abbreviations used in this paper: $\mathrm{CHO}$, Chinese hamster ovary; ERCC1, human DNA excision repair gene, cross-complementing CHO mutant cell lines of complementation group 1; RT/PCR, reverse transcription PCR; XPAC, human xeroderma pigmentosum group A correcting gene.

The Journal of Clinical Investigation, Inc.

Volume 94, August 1994, 703-708
Chinese hamster ovary [CHO] mutant cell lines of complementation group 1) and XPAC (the human excision repair gene that corrects the defect in xeroderma pigmentosum group A cells) have been cloned $(4,5)$. Several studies using mutant human and hamster cell lines that are defective in either of these genes, and their transfected derivatives, and studies in human tumor tissues indicate that the products encoded by these genes are involved in the excision repair of platinum-DNA adducts (6-9).

We have been interested in ascertaining the relative levels of expression of excision repair genes in malignant cells from cancer patients receiving platinum-based therapy (6). Currently accepted models of excision repair suggest that the damage recognition/excision step is rate-limiting to the excision repair process (3). Studies on the homology of human excision repair genes with bacterial and yeast excision repair genes suggest that ERCC1 and XPAC may be the genes primarily involved in the recognition and excision of bulky DNA adducts $(5,10-$ 12). This occurs with the help of putative helicases encoded by ERCC2, ERCC3, and ERCC6 $(2,13)$.

The present study examines relative mRNA levels of expression of ERCC1 and XPAC in ovarian cancer tissues. We also assess the levels of an alternatively spliced species of ERCC1 mRNA which does not contain exon VIII and is presumed to be nonfunctional. These studies have been done in tumor tissues taken from a cohort of 28 patients with ovarian cancer, before the initiation of platinum-based therapy. We believe that assessing patterns of mRNA expression of ERCC and XP genes may assist in understanding the molecular control of cellular resistance to DNA-damaging agents.

\section{Methods}

Tissues studied. Fresh tumor tissues were obtained from 28 patients with ovarian cancer. These tissues were obtained before treatment with cisplatin- or carboplatin-based chemotherapy. Patients from whom tissues were obtained participated in either of three approved experimental treatment protocols for advanced stage ovarian cancer that have been reported previously by the Medicine Branch of the National Cancer Institute (unpublished observations ${ }^{2}, 14-16$ ). Disease was followed by physical exam and by radiographic means, including abdominopelvic CT scan and/or ultrasound examination.

Complete response was defined as complete eradication of all evaluable disease, confirmed by peritoneoscopy. Partial response was defined as a $>50 \%$ reduction in the sum of the products of the perpendicular diameters of all measurable lesions lasting at least 1 mo. Progressive disease was a $>25 \%$ increase in the sum of the products of the perpendicular diameters of all measurable lesions or the appearance of new

2. Reed, E., M. L. Rothenberg, and E. Kohn, unpublished data from approved experimental treatment protocol. "High dose carboplatin, cisplatin, and cyclophosphamide in the initial therapy of advanced stage epithelial ovarian cancer." Medicine Branch, National Cancer Institutes. Trial completed in 1992. 


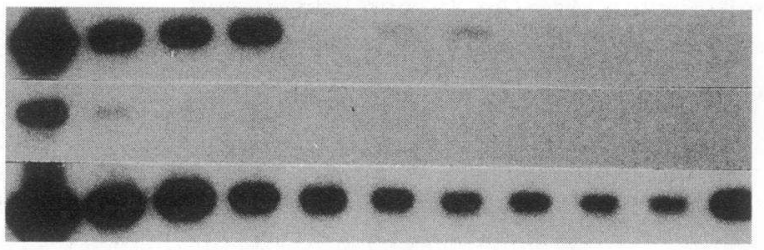

\section{BLOT \#2 NON-RESPONDERS}

\section{PATIENT \# $121314151617 \quad 18$}

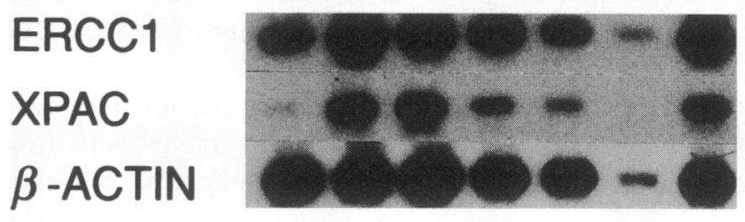

\section{BLOT \#3 (RESPONDERS) AND NON-RESPONDERS PATIENT \# (19)20 21 22(23)(24)(25)26 2728}

ERCC 1
XPAC
$\beta$-ACTIN

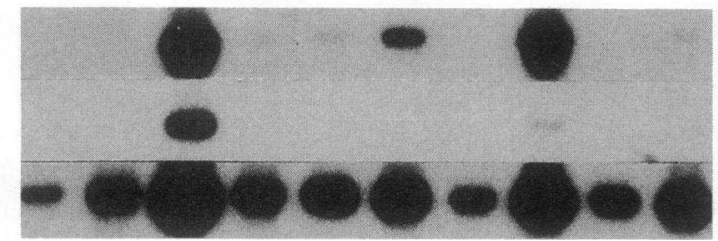

Figure 1. Autoradiographs generated by RT/ PCR-amplified RNA from ovarian cancer tissues, after hybridization of Southern blots with radiolabeled probes for ERCC1, XPAC, and $\beta$-actin. Samples 1-11, 19, and 23-25 (blots 1 and 3) represent 15 tumor tissues from patients responding to platinum-based therapy; samples 12-18, 20-22, and 26-28 (blots 2 and 3) represent 13 tumor tissues from patients resistant to platinum-based therapy. lesions. Stable disease included those clinical circumstances which did not fit the definitions of objective response nor progression. Progressive disease and stable disease patients are included in the nonresponder category. Complete response and partial response are included in the responder category. By these criteria, there are 15 patients who were responders and 13 nonresponders in the cohort.

In vitro studies were performed using the ovarian cancer cell line A2780/CP70, which has been described previously by our laboratory (17).

$P C R$ analyses. A reverse transcription/polymerase chain reaction (RT/PCR)-based assay system (6) was used to determine the level of expression of ERCC1, XPAC, and $\beta$-actin. Tissues were stored at $-80^{\circ} \mathrm{C}$ and extracted for total RNA by hot phenol/chloroform extraction (18). cDNA was obtained from $10 \mu \mathrm{g}$ of total RNA by reverse transcription using oligo-dT primers (Reverse Transcription System; Promega Corp., Madison, WI). cDNAs were washed and concentrated by ultrafiltration (Amicon, Beverly, MA) and resuspended to $100 \mu \mathrm{l}$ in low TE buffer (10 mM Tris, $\mathrm{pH} 8.0$, and $0.1 \mathrm{mM}$ EDTA).

For ERCC1, primers and RT/PCR conditions were selected to affect amplification of a 481-bp segment, from 245 to 725 of the ERCC1 cDNA nucleotide sequence (19) and including exons III to VI of the ERCC1 gene (20). For XPAC, primer and PCR conditions were optimized for amplification of a 531-bp segment from base 164 to base 694 (5) which spans a region that extends from within exon I to exon V (21). Primers chosen for $\beta$-actin spanned a 731-bp segment of the coding region of the $\beta$-actin gene and extended from base 269 of exon II to base 1535 in exon IV (22).

Aliquots of $7.5 \mu \mathrm{l}$ of the cDNA preparation from each sample were thus amplified by RT/PCR for 30 cycles for ERCC1 and for $\beta$-actin and for 40 cycles for XPAC. The GeneAmp PCR reagent kit with AmpliTaq DNA polymerase (Perkin-Elmer Cetus Instruments, Norwalk, CT) was used for each gene. Aliquots of amplified DNA were electrophoresed through a $1.5 \%$ agarose gel. Amplified DNA was visualized by ethidium bromide staining, photographed over an ultraviolet (UV) transilluminater (Hoefer Scientific Instruments, San Francisco, CA), and transferred to Hybond N+ membrane (Amersham International, Buckinghamshire, UK). Oligonucleotides (26-mers) from the central region of each amplified sequence were end-labeled with $\left[{ }^{32} \mathrm{P}\right] \tau$ ATP (Amersham International) using T4 polynucleotide kinase (Stratagene, La Jolla, CA) and were used as the respective probes. Oligonucleotides used as primers and probes for RT/PCR-based analysis of ERCC1 expression were synthesized on a DNA synthesizer (Biosearch Inc., San Rafael, CA) and purified by polyacrylamide gel electrophoresis (23). Primers and probes for XPAC and $\beta$-actin PCRs were synthesized by Lofstrand Laboratories Ltd. (Gaithersburg, MD).

Numerical values for the expression of the ERCC1 and XPAC genes in tumor tissue specimens were obtained as follows. For each sample, the densitometric readout of the autoradiographic signal generated by the RT/PCR-amplified DNA when hybridized to ${ }^{32} \mathrm{P}$-labeled ERCC1 or XPAC probe was divided by the densitometric reading for $\beta$-actin. For purposes of comparison, the sample with the highest ERCC1/actin value was assigned the value of " 1 ," and all other samples were expressed relative to that value. For XPAC expression, the sample with the highest XPAC/actin value was assigned the value of 1 , and the other samples were expressed relative to this value.

Aliquots of $3 \mu \mathrm{l}$ of the cDNA preparation from samples expressing detectable levels of ERCC1 RT/PCR product were analyzed for alternative splicing of ERCC1. Primers flanking exon VIII, which is 72 bases 
Table I. Relative Levels of ERCCI and XPAC Gene Expression in Ovarian Tumor Tissue in Relation to Response

\begin{tabular}{lrrr}
\hline \multicolumn{1}{c}{ Gene } & Range & Median & Mean \pm SD \\
\hline ERCC 1 & & & \\
Responders $(n=15)$ & $<0.01-1.00$ & $<0.01$ & $0.21 \pm 0.32$ \\
Nonresponders $(n=13)$ & $<0.01-0.94$ & 0.50 & $0.46 \pm 0.34$ \\
& & & $P=0.059$ \\
XPAC & & & \\
Responders $(n=15)$ & $<0.01-0.45$ & $<0.01$ & $0.03 \pm 0.12$ \\
Nonresponders $(n=13)$ & $<0.01-1.00$ & 0.09 & $0.31 \pm 0.37$ \\
& & & $P=0.011$
\end{tabular}

long, were used to detect the presence and relative proportions of full length and alternatively spliced ERCC1 mRNA in tissue samples (19). DNA segments of 196 and 268 baselengths were obtained on amplification of the ERCC1 cDNA sequence extending from base 692 to base 959 (19). RT/PCR was conducted for 30 cycles. Southern blots of amplified segments were hybridized with a probe 26 bases long extending from base 764 to $789,5^{\prime}$ of exon VIII. The ratio of autoradiographic signals thus generated to the autoradiographic signal obtained for $\beta$-actin for each sample was used to determine the levels of the full length ERCC1 mRNA (with the 72-base-long exon VIII) and an alternatively spliced species of ERCC1 mRNA (without exon VIII). When assessing alternative splicing of ERCC1 mRNA, the human T lymphocyte cell line, H9 (24), was used as an internal control.

Statistical analyses. The relationship between response to therapy and expression of excision repair genes was examined for statistical significance using the Student's $t$ test with the Statworks program on a Macintosh SE Computer (Apple Computers, Inc., Palo Alto, CA). Twosided $P$ values are shown in the tables and text. Curve fitting analyses to obtain correlation coefficients were similarly conducted using the CricketGraph program (Computer Associates International, Inc., Islandia, NY).

\section{Results}

Fig. 1 shows autoradiographs of RT/PCR-amplified mRNA from the 28 patients studied in the cohort. Detectable levels of ERCC1 mRNA were seen in 19 tumor specimens. Detectable levels of ERCC1 were seen in 11 out of 13 tumors that were resistant to therapy, but in only 7 out of 15 tumors that were clinically sensitive to therapy. For XPAC, detectable mRNA levels were seen in 8 out of 15 nonresponders and in 2 out of 13 responders.

The median level of ERCC1 expression for the cohort of 28 patients was 0.18 ; and for XPAC the median level of expression was not detectable $(<0.01)$. When responders and nonresponders are assessed as a function of the median expression levels of these two genes, higher levels of expression were consistently seen in the nonresponder group. In nonresponders, 9 out of 13 showed ERCC1 levels higher than the median, and 8 out of 13 showed XPAC levels higher than the median. In responding patients, 5 out of 15 showed ERCC1 levels higher than the median, and 2 out of 15 showed XPAC levels higher than the median. Concurrent expression levels for both genes, which were higher than the median, were seen in 8 out of 13 tumors that were clinically resistant to platinum-based therapy and in 2 out of 15 tumors that were clinically sensitive.

Table I shows the summary values for ERCC1 and XPAC for responders and nonresponders. The difference between dis-
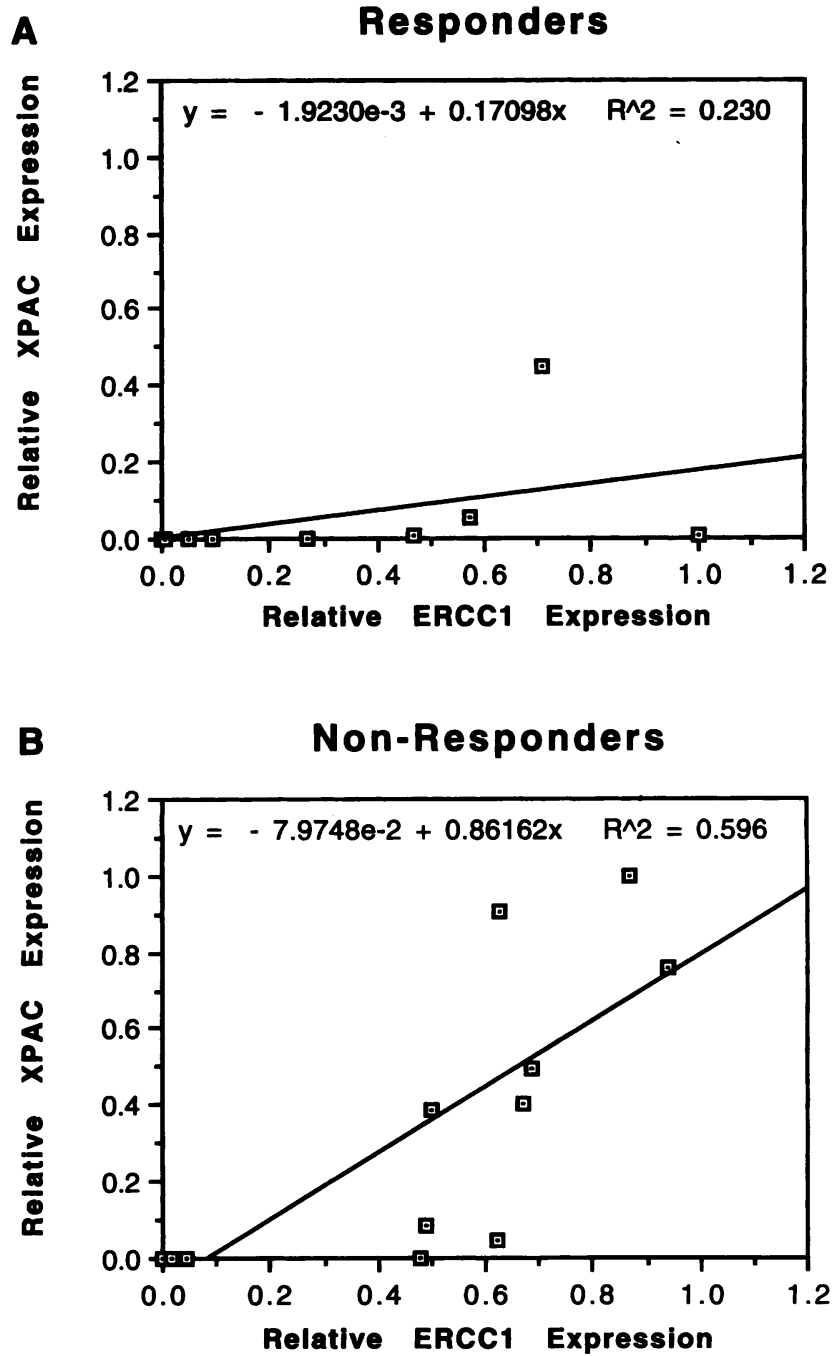

Figure 2. Correlation coefficients obtained after simple curve-fit analysis of the relative expression of ERCC1 and XPAC genes in ovarian tumor tissues from responders $(A)$ and nonresponders $(B)$.

ease response groups for XPAC is statistically significant $(P$ $=0.011)$, but for ERCC1 the relationship borders on significance $(P=0.059)$.

Fig. 2 shows the graphic relationship between ERCC1 and XPAC for responding patients $(A)$ and for nonresponders $(B)$. For tumors sensitive to platinum-based therapy, XPAC expression is consistently extremely low regardless of the ERCC1 level (Fig. 2 A). For tumors resistant to platinum-based therapy, there is a suggestion of coordinated expression of these two genes in those tissues (Fig. $2 \mathrm{~B}$ ). In platinum-resistant tumors, the shift of the curve to the right suggests that ERCC1 expression may be upregulated first, followed by upregulation of XPAC.

Fig. 3 shows autoradiographs of the 19 samples assessed for the full length transcript of ERCC1, as well as the alternatively spliced species. In both responders and nonresponders, expression levels of both species were highly variable. Table II shows a summary of the numerical values generated from Fig. 3. For the full length transcript of ERCC1, the difference between responders and nonresponders was statistically signifi- 

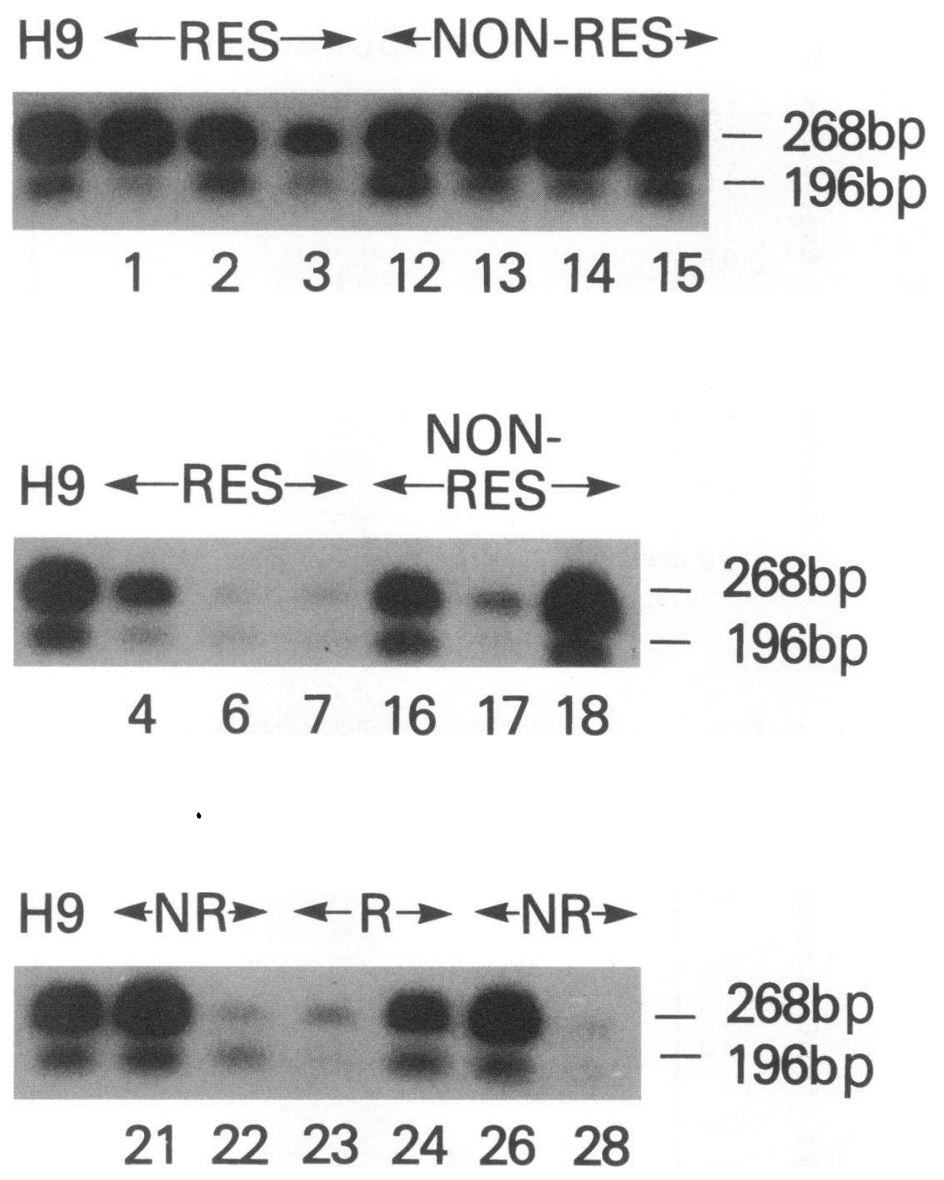

Figure 3. Alternative splicing of ERCC1 mRNA in 19 ovarian tumor tissues. Autoradiographs generated by Southern blots of amplified segments representing the full length transcript and the alternatively spliced species of ERCC1 mRNA are shown. Blots were hybridized with a probe extending from base 764 to base 789, 5' of exon VIII in the ERCC1 cDNA sequence. The numbers in the figure correspond to the patient numbers from Fig. 1. cant $(P=0.026)$, whereas for the alternatively spliced species the difference only bordered on significance $(P=0.058)$. Table II also shows a summary of the percentage of total ERCC1 which was nonfunctional (lacking exon VIII) in responding patients and in nonresponders. In responding patients, the per-

Table II. Relative Levels of Alternatively Spliced Species of ERCC1 mRNA in Ovarian Tumor Tissue in Relation to Response

\begin{tabular}{lccc}
\hline ERCC1 species & Range & Median & Mean \pm SD \\
\hline $\begin{array}{l}\text { Full length transcript of } \\
\quad \text { ERCC1 }\end{array}$ & & & \\
Responders $(n=8)$ & $0.05-0.36$ & 0.18 & $0.19 \pm 0.12$ \\
$\quad$ Nonresponders $(n=11)$ & $0.07-1.00$ & 0.38 & $0.44 \pm 0.27$ \\
& & & $P=0.026$ \\
Alternatively spliced & & & \\
$\quad$ species of ERCC1 & & & \\
Responders $(n=8)$ & $0.003-0.10$ & 0.04 & $0.05 \pm 0.04$ \\
$\quad$ Nonresponders $(n=11)$ & $0.01-0.21$ & 0.10 & $0.10 \pm 0.07$ \\
& & & $P=0.058$ \\
Percentage of total & & & \\
$\quad$ ERCC1 that is & & & \\
$\quad$ alternatively spliced & & 18.0 & $21.9 \pm 17.9$ \\
Responders $(n=8)$ & $1.5-58.3$ & 13.2 & $22.6 \pm 20.0$ \\
$\quad$ Nonresponders $(n=11)$ & $3.5-70.6$ & & \\
& & &
\end{tabular}

centage varied from 1.5 to $58.3 \%$, and in nonresponders the percentage varied from 3.5 to $70.6 \%$.

A2780/CP70 cells were assessed for ERCC1 and XPAC mRNA expression, based on whether cells were in the exponential growth phase or in confluence. mRNA levels of XPAC were not different between exponentially growing cells and confluent cells. Surprisingly, mRNA levels of ERCC1 were slightly higher in confluent cells (data not shown).

\section{Discussion}

DNA repair is one of the three major molecular mechanisms through which cells become resistant to platinum compounds (25). Studies in human ovarian cancer cells (17), in human T lymphocytes (26), and in murine L1210 leukemia cells $(27,28)$ all suggest that at low levels of platinum resistance (up to 1015-fold over baseline) DNA repair is the most important mechanism of resistance.

The DNA repair gene XPAC has generally been studied with respect to UV repair deficiency states such as xeroderma pigmentosum (29). This is the first report relating XPAC gene expression to the clinical treatment of a human malignant disease. ERCC1 has been studied in human ovarian cancer cells (6) and in chronic lymphocytic leukemia (30); but it was not determined in either study whether there was a relationship between processing of the RNA of the gene and tumor cell resistance. Current models suggest that ERCC1 and XPAC may work together to recognize and excise covalent DNA damage 
from intact DNA (3). This report suggests that in human ovarian cancer these two genes are directly related to clinical resistance to the DNA-damaging platinum compounds and supports the concept that these two genes work together in this process.

The XPAC gene product exhibits homology to the bacterial and yeast proteins uvrA and RAD14, respectively $(5,10)$. The section of XPAC mRNA that is amplified by PCR in our study, ranging from exon I to possibly exon $V(21)$, includes segments of the XPAC protein that are essential for DNA repair function (31). These segments include a glutamic acid cluster in exon II that may bind histones and the DNA-binding zinc finger motif in exon III (31). The XPAC gene product is thus involved in the recognition of bulky DNA adducts and is essential for excision repair of bulky adducts $(3,8,10)$. The impaired ability of XPA-derived fibroblast cell lines to effect the repair of platinum-DNA adducts has been well documented $(7,32,33)$. In our study, significantly higher levels of XPAC mRNA were detected in the tumor tissues of patients resistant to platinumbased therapy, compared with tissues from patients responding to therapy. This is the first report suggesting the clinical importance of high levels of XPAC gene expression in determining the ability of malignant tissue to process platinum-DNA adducts.

The ERCC1 gene exhibits homology to the yeast RAD10 gene (19), which forms an endonucleolytic complex with RAD1, and is involved in the excision of bulky DNA adducts $(11,12)$. When transfected into DNA-repair deficient $\mathrm{CHO}$ cells, ERCC1 confers cellular resistance to cisplatin along with the ability to repair platinum-DNA adducts (9). Our present study indicates that concurrent high levels of expression of both ERCC1 and XPAC may translate into augmented tumor cell resistance to platinum-based therapy in ovarian cancer tissue. Concordance of ERCC1 and XPAC mRNA levels, as indicated by a high correlation coefficient, occurs in the tissues from patients resistant to platinum-based therapy. Thus, the concurrent augmentation in the expression of the XPAC and ERCC1 genes (which recognize and cleave bulky adducts) may result in the increased removal of DNA damage affected by platinum therapy. It is interesting to note that, in ovarian tumor tissue, upregulation of ERCC1 appears to occur before an upregulation of XPAC gene expression (see Fig. $2 \mathrm{~B}$ ). A similar relationship between ERCC1 and other ERCC genes was observed in nonmalignant bone marrow from cancer patients and also in human ERCC1-transfected CHO cells (34). In that study, the regulation of ERCC1 expression appeared to dictate the regulation of ERCC2 and ERCC6.

The presence of an alternatively spliced species of ERCC1 mRNA lacking a 72-bp exon was first reported in a study of poly(A) ${ }^{+}$RNA from HeLa and K562 cell lines and of human ERCC1 cDNA clones (19). In that study, transfection experiments indicated that only the cDNA from the full human ERCC1 transcript (which includes exon VIII) could complement the excision repair defect for UV and mitomycin C. In our study, significantly higher levels of the full ERCC1 mRNA transcript are associated with a lack of response to platinumbased therapy. In our analysis, patients resistant to platinumbased therapy also exhibit higher levels of the ERCC1 transcript devoid of exon VIII, but the difference is not statistically significant.

For total ERCC1, the difference between responders and nonresponders had a $P$ value of 0.059 , and for nonfunctional ERCC1 the $P$ value was 0.058 . One report has suggested that the smaller "nonfunctional" transcript for ERCC1 may indeed have a "helper" function for the repair of UV- and mitomycin C-induced DNA damage in some settings (35). Since the $P$ value for the full "functional" transcript for ERCC1 is 0.026 , we believe that our clinical observations are consistent with the laboratory model regarding the functions of the full transcript and of the transcript lacking exon VIII.

The rate-limiting step in DNA excision repair is the damage recognition/excision step, which is mediated by genes of the ERCC and XP groups (3). Here, we have shown that mRNA levels of two of the key genes in this process, ERCC1 and XPAC, are directly related to clinical resistance to platinum compounds in human ovarian cancer. This suggests that the concurrent expression of both enzymes may increase the removal of the DNA damage effected by platinum therapy. Unraveling the molecular processes involved in clinical resistance to this type of therapy is the first step in the development of novel ways to selectively eradicate human malignant disease.

\section{References}

1. Cleaver, J. E. 1990. Do we know the cause of xeroderma pigmentosum? Carcinogenesis (Oxf.). 11:875-882.

2. Hoeijmakers, J. H. J., and D. Bootsma. 1990. Molecular genetics of eukaryotic DNA excision repair. Cancer Cells (Cold Spring Harbor). 2:311-320.

3. Shivji, M. K. K., M. K. Kenny, and R. D. Wood. 1992. Proliferating cell nuclear antigen is required for DNA excision repair. Cell. 69:367-374.

4. Westerveld, A., J. H. J. Hoeijmakers, M. van Duin, J. de Wit, H. Odijk, A. Pastink, R. D. Wood, and D. Bootsma. 1984. Molecular cloning of a human DNA repair gene. Nature (Lond.). 310:425-428.

5. Tanaka, K., N. Miura, I. Satokata, I. Miyamoto, M. C. Yoshida, Y. Satoh, S. Kondo, A. Yasui, H. Okayama, and Y. Okada. 1990. Analysis of a human DNA excision repair gene involved in group A xeroderma pigmentosum and containing a zinc-finger domain. Nature (Lond.). 348:73-76.

6. Dabholkar, M., F. Bostick-Bruton, C. Weber, V. Bohr, C. Egwuagu, and E. Reed. 1992. ERCC1 and ERCC2 expression in malignant tissues from ovarian cancer patients. J. Natl. Cancer Inst. 84:1512-1517.

7. Dijt, F. J., A. M. J. Fichtinger-Schepman, F. Berends, and J. Reedjik. 1988. Formation and repair of cisplatin-induced adducts to DNA in cultured normal and repair-deficient human fibroblasts. Cancer Res. 48:6058-6062.

8. Hansson, J., L. Grossman, T. Lindahl, and D. Wood. 1990. Complementation of the xeroderma pigmentosum DNA repair synthesis defect with Escherichia coli UvrABC proteins in a cell free system. Nucleic Acids Res. 18:35-40.

9. Lee, K. B., R. J. Parker, V. Bohr, T. Cornelison, and E. Reed. 1993. Cisplatin sensitivity/resistance in UV-repair deicient Chinese hamster ovary cells of complentation groups 1 and 3. Carcinogenesis (Oxf.). 14:2177-2180.

10. Bankmann, M., L. Prakash, and S. Prakash. 1992. Yeast RAD14 and human xeroderma pigmentosum group A DNA-repair genes encode homologous proteins. Nature (Lond.). 355:555-558.

11. Tomkinson, A. E., A. J. Bardwell, L. Bardwell, N. J. Tappe, and E. C. Friedberg. 1993. Yeast DNA repair and recombination proteins RAD1 and RAD10 constitute a single-stranded-DNA endonuclease. Nature (Lond.). 362:860-862.

12. Wang, Z., X. Wu, and E. C. Friedberg. 1993. Nucleotide excision repair of DNA in cell-free extracts of the yeast Saccharomyces cerevisiae. Proc. Natl. Acad. Sci. USA. 90:4907-4911.

13. Hoeijmakers, J. H. J. 1991. How relevant is the Escherichia coli UvrABC model for excision repair in eukaryotes? J. Cell Sci. 100:687-691.

14. Rothenberg, M. L., R. F. Ozols, E. J. Glatstein, S. M. Steinberg, E. Reed, and R. C. Young. 1992. Dose-intensive induction therapy with cyclophosphamide, cisplatin, and abdominal radiation in advanced stage epithilial ovarian cancer. $J$. Clin. Oncol. 10:727-734.

15. Reed, E., J. Janik, M. A. Bookman, M. Rothenberg, J. Smith, R. C. Young R. F. Ozols, L. VanderMolen, E. C. Kohn, J. Jacob, and T. L. Cornelison. 1993. High dose carboplatin and rGM-CSF in advanced stage recurrent ovarian cancer. J. Clin. Oncol. 11:2118-2126.

16. Rothenberg, M. L., Y. Ostchega, S. M. Steinberg, R. C. Young, S. Hummel, and R. F. Ozols. 1988. High dose carboplatin with diethyldithiocarbamate chemoprotection in the treatment of women with relapsed ovarian cancer. J. Natl. Cancer Inst. 80:1488-1492.

17. Parker, R. J., A. Eastman, F. Bostick-Bruton, and E. Reed. 1991. Acquired cisplatin resistance in human ovarian cancer cells is associated with enhanced repair of cisplatin-DNA lesions and reduced drug accumulation. J. Clin. Invest. 87:772-777.

18. Wahl, G. M., R. A. Padgett, and G. R. Stark. 1979. Gene amplification 
causes overproduction of the first three enzymes of UMP synthesis in $N$-(phosphonacetyl)-L-aspartate-resistant hamster cells. J. Biol. Chem. 254:8679-8684.

19. van Duin, M., J. de Wit, H. Odijk, A. Westerveld, A. Yasui, M. Koken, J. H. J. Hoeijmakers, and D. Bootsma. 1986. Molecular characterization of the human excision repair gene ERCC-1: cDNA cloning and amino acid homology with the yeast DNA repair gene RAD10. Cell. 44:913-923.

20. Hoeijmakers, J. H. J., G. Weeda, C. Troelstra, M. van Duin, A. Westerveld, A. van der Eb, and D. Bootsma. 1989. Molecular genetic dissection of mammalian excision repair. In DNA Repair Mechanisms and Their Biological Implications in Mammalian Cells. M. W. Lambert and J. Laval, editors. Plenum Publishing Corp., New York. 563-574.

21. Satokata, I., K. Tanaka, S. Yuba, and Y. Okada. 1992. Identification of splicing mutations of the last nucleotides of exons, a nonsense mutation, and a missense mutation of the XPAC gene as causes of group A xeroderma pigmentosum. Mutat. Res. 273:203-212.

22. Nakajima-Iijima, S., H. Hamada, P. Reddy, and T. Kakunaga. 1985. Molecular structure of the human cytoplasmic $\beta$-actin gene: interspecies homology of sequences in the intron. Proc. Natl. Acad. Sci. USA. 82:6133-6137.

23. Maniatis, T., E. F. Fritsch, and J. Sambrook. 1989. Molecular Cloning: A Laboratory Manual, 2nd edition, volume 2. Cold Spring Harbor Laboratory, Cold Spring Harbor, NY. 660 pp.

24. Popovic, M., E. Read-Connole, and R. C. Gallo. 1984. T4 positive human neoplastic cell lines susceptible to and permissive for HTLV-III. Lancet. ii:14721473.

25. Reed, E. 1993. Platinum analogs. In Cancer-Principles and Practice of Oncology, 4th edition. V. T. DeVita, Jr., S. Hellman, and S. A. Rosenberg, editors. J. B. Lippincott Co., Philadelphia. 390-399.

26. Dabholkar, M., R. Parker, and E. Reed. 1992. Determinants of cisplatin sensitivity in non-malignant, non-drug-selected human T cell lines. Mutat. Res. 274:45-56.

27. Eastman, A., N. Schulte, N. Sheibani, and C. M. Sorenson. 1988. Mecha- nisms of resistance to platinum drugs. In Platinum and Other Metal Coordination Compounds in Cancer Chemotherapy. M. Nicolini, editor. Martinus Nijhoff Publishing, Boston. 178-196.

28. Sheibani, N., M. M. Jennerwein, and A. Eastman. 1989. DNA repair in cells sensitive and resistant to cis-diamminedichloro-platinum(II): host cell reactivation of damaged plasmid DNA. Biochemistry. 28:3120-3124.

29. Wood, R. D., and T. Lindahl. 1990. A gene for tumor prevention. Nature (Lond.). 348:13-14.

30. Geleziunas, R., A. McQuillan, A. Malapetsa, M. Hutchinson, D. Kopriva, M. A. Wainberg, J. Hiscott, J. Bramson, and L. Panasci. 1991. Increased DNA synthesis and repair-enzyme expression in lymphocytes from patients with chronic lymphocytic leukemia resistant to nitrogen mustards. J. Natl. Cancer Inst. 83:557564.

31. Miyamoto, I., N. Miura, H. Niwa, J. Miyazaki, and K. Tanaka. 1992. Mutational analysis of the structure and function of the xeroderma pigmentosum group A complementing protein. Identification of essential domains for nuclear localization and excision repair. J. Biol. Chem. 267:12182-12187.

32. Chu, G., and P. Berg. 1987. DNA cross-linked by cisplatin: a new probe for the DNA repair defect in xeroderma pigmentosum. Mol. Biol. \& Med. 4:277290.

33. Poll, E. H. A., P. J. Abrahams, F. Arwert, and A. W. Eriksson. 1984 Host cell reactivation of cis-diamminedichloroplatinum(II)-treated SV40 DNA in normal human, Fanconi anaemia and xeroderma pigmentosum fibroblasts. Mutat. Res. 132:181-187.

34. Dabholkar, M., F. Bostick-Bruton, C. Weber, C. Egwuagu, V. A. Bohr and E. Reed. 1993. Expression of excision repair genes in non-malignant bone marrows from cancer patients. Mutat. Res. 293:151-160.

35. Belt, P. B. G. M., M. F. van Oosterwijk, H. Odijk, J. H. J. Hoeijmakers and C. Backendorf. 1991. Induction of a mutant phenotype in human repair proficient cells after overexpression of a mutated human DNA repair gene. Nucleic Acids Res. 19.5633-5637. 